\begin{tabular}{|l|l|}
\hline \begin{tabular}{l|l|} 
ESCOLA DE COMUNICAÇÃO, \\
ARTES E DESIGN
\end{tabular} & $\begin{array}{l}\text { mídia, cultura e tecnologia } \\
\text { Revista FAMECOS, Porto Alegre, v. 28, p. 1-14, jan.-dez. } 2021 \\
\text { e-ISSN: 1980-3729 | ISSN-L: 1415-0549 }\end{array}$ \\
\hline PUCRS & FAMECOS \\
\hline https://dx.doi.org/10.15448/1980-3729.2021.1.40244 & \\
\hline
\end{tabular}

SEÇÃO: JORNALISMO

\title{
O testemunho na construção narrativa de personagens em noticiários criminais
}

\author{
The testimony in the narrative construction of the characters in criminal TV news \\ El testimonio en la construcción narrativa de personajes en la noticia criminal
}

\author{
Hendryo Anderson \\ André ${ }^{1}$ \\ orcid.org/0000-0002-2357-9743 \\ hendryoandre@gmail.com
}

Recebido em: 27 fev. 2021.

Aprovado em: 19 ago. 2021.

Publicado em: 5 nov. 2021.

\section{(c) (1)}

Artigo está licenciado sob forma de uma licença Creative Commons Atribuição 4.0 Internacional.
Resumo: O objetivo é refletir sobre o papel do testemunho na construção narrativa de personagens em noticiários criminais. Ligada ao estatuto da confissão, essa técnica social ganhou novas dimensões em sociedades midiatizadas e se tornou relevante da produção à recepção. Para atingir o objetivo, propõe-se um diálogo entre a forma como os personagens são construidos narrativamente e a maneira como o público produz sentidos aos crimes exibidos em dois telejornais. O texto parte de uma discussão teórica sobre jornalismo, confissão e testemunho. Após a apresentação dos telejornais e do público, ancora-se nos resultados de uma análise de conteúdos realizada em 80 edições nos noticiários criminais Balanço Geral e Tribuna da Massa, ambos veiculados em Curitiba, no Paraná, e em um estudo de recepção produzido a partir de entrevistas em profundidade com 18 telespectadores desses programas. Entre os resultados observa-se a personificação das fontes oficiais, a substituição de testemunhas oculares por tecnologias de vigilância e a ascensão de um tipo especial de personagem, o familiar, aspectos que contribuem para o engajamento do público.

Palavras-chave: Telejornalismo. Testemunho. Personagem.

Abstract: The aim of this study is to reflect on the role of testimony in the construction of narrative characters in criminal news. Social technique is part of the confession statute, it has gained new dimensions in mediatized societies and it has become relevant from production to reception. To achieve the aim, the research proposes a dialogue between the form of narrative construction of the characters and the manner the audience produces meanings for the crimes shown on two newscasts. The text starts from a theoretical discussion about journalism, confession and testimony. After the presentation of both TV news and the viewers, the study presents the results of a content analysis of 80 editions of the television programs Balanço Geral and Tribuna da Massa. The transmission of both programs takes place in Curitiba, Paraná. Then, the argument focuses on a reception study produced from in-depth interviews with 18 viewers of the two newscasts. Among the results are the personification of official sources, the replacement of eyewitnesses by surveillance technologies and the rise of a special type of character, the familiar. These characteristics collaborate to engage the television news audience.

Keywords: Television journalism. Witness. Character.

Resumen: El objetivo es reflexionar sobre el papel del testimonio en la construcción de personajes narrativos en la noticia criminal. Vinculada al estatus de la confesión, esta técnica social adquirió nuevas dimensiones en las sociedades mediatizadas y adquirió relevancia desde la producción hasta la recepción. Para lograr el objetivo, se propone un diálogo entre la forma en que se construyen narrativamente los personajes y la forma en que la audiencia produce significados para los crimenes mostrados en dos noticieros. El texto parte de una discusión teórica sobre periodismo, confesión y testimonio. Luego de la presentación de la noticia y al público, se ancla en los resultados de un análisis de contenido realizado en 80 ediciones en los reportajes de noticias criminales Balanço Geral y Tribuna da 
Massa, ambos transmitidos en Curitiba, Paraná, y en un estudio de recepción elaborado a partir de entrevistas en profundidad a 18 espectadores de estos programas. Entre los resultados se encuentran la personificación de fuentes oficiales, la sustitución de testigos presenciales por tecnologías de vigilancia y el surgimiento de un tipo especial de carácter, el familiar, caracteristicas que contribuyen a la implicación del público.

Palabras clave: Teleperiodismo. Testimonio. Personaje.

\section{Introdução}

Ação inseparável da prática e dos sentidos produzidos pelo jornalismo, o testemunho teve origem no campo da religião a partir do relato de milagres, experiência que promovia verdades, curiosamente, descartadas sob o prisma da empiria (BRITO, 2012). O termo se reconfigurou na modernidade, sobretudo desde o século XVIII, quando princípios do capitalismo e da democracia, respectivamente, passaram a estruturar os sistemas econômico e político. Nessa lógica, com a finalidade de compreender aspectos de ocorrência do testemunho no jornalismo, no presente texto, as atenções foram voltadas para o papel desse dispositivo na construção narrativa de personagens em noticiários criminais, gênero noticioso que se popularizou no Brasil, em especial, a partir de meados da década de 1990 (FRANÇA, 2006).

O jornalismo se institucionalizou por se respaldar na premissa de narrar, perante um estatuto próprio, aspectos da realidade cujos desdobramentos deveriam contribuir para o interesse público. Em geral, a atividade é legitimada por histórias de pessoas ou grupos sociais envolvidos em fatos que, sob a ótica institucional, mereçam visibilidade, noção aqui entendida como um imperativo da própria ideia de democracia. Como a visibilidade tem cerne político, todo processo comunicativo é sujeito a conflitos. Na produção e na recepção de produtos jornalísticos, por exemplo, há certas convenções que buscam organizar, por meio de representações sociais (MOSCOVICl, 2015), a leitura da realidade; e o testemunho é parte estrutural disso. Se testemunhar remete à partilha de experiências, em sociedades midiatizadas, dependentes de "processos de mediação de base tecnológica e institucional" (COULDRY;
HEPP, 2020, p. 14), todo fato transformado em narrativa é concebido por essa lógica.

Frosh e Pinchevski (2008) descrevem três vertentes para entender a relevância do testemunho nas sociedades contemporâneas. Embora lidas conjuntamente, a primeira se relaciona a depoimentos na midia (witnesses in the media), enquanto as demais se vinculam ao espaço-tempo das mediações, dimensão na qual os temas veiculados ganham sentidos plurais (MARTÍN-BARBERO, 2015). Nesse contexto, a própria midia é produtora e produto de testemunhos (witnesses by the media), o que dialoga com o posicionamento do público como testemunha dos eventos representados pelos meios de comunicação (witnesses through the media).

Entre várias questões, é necessário observar que tais noções de testemunho lançam mão nas narrativas ancoradas no real de aproximações entre personagens e pessoas, entre ficção e realidade, algo potencializado no século XIX, quando se inaugurou uma visão de natureza psicológica dos personagens (BRAIT, 2017; SODRÉ, 1988). Sustentados por matrizes narrativas, os vínculos entre personagem e pessoa reiteram que as representações sociais operam no âmbito da cultura, e que legitimam processos de identificação a partir de temas que ganharam abordagem pública de forma genuína.

As noções de representação e de visibilidade se tornaram mais complexas ao longo do século $X X$ devido a novos processos de produção e de circulação. De modo singular, a televisão, enquanto integradora do cotidiano, associou-se, em definitivo, às lógicas de socialização. Pela capacidade proporcionar experiências individuais e, ao mesmo tempo, coletivas, o meio de comunicação se tornou o "lugar onde ecoam e ganham visibilidade os diferentes atores da vida social" (FRANÇA, 2006, p. 28).

Esse espaço de visibilidade funda-se em densas tensões sociais, algo que dialoga, mas também ultrapassa a tecnologia em si, e que acarreta processos de estigmatização e de invisibilidade social a grupos marginalizados. Nessa perspectiva, entre as principais questões de visibilidade 
está a violência, cujos efeitos têm ocasionado mais 60 mil mortes anuais no pais (BRASIL, 2018). O fenômeno é um dos ônus mais visiveis da modernidade tardia (ORTIZ, 2001), processo consolidado nos anos 1970 e que implementou politicas modernizadoras com vistas a compensar o atraso econômico - não por coincidência, nesse periodo a televisão se estabeleceu como uma instituição social relevante.

O jornalismo voltado à cobertura de crimes, mediante a experiência da sociedade brasileira com a televisão, integrou um processo de midiatização relativamente singular, iniciado ainda na década de 1960, período que atrações televisivas ligadas à violência se multiplicaram (RIBEIRO; SACRAMENTO, 2010). Embora tenham sido reduzidas durante a ditadura, elas ganharam força desde a redemocratização, sobretudo após a criação do Plano Real. O público desses programas, em geral, é formado por pessoas com baixo ou nenhum acesso à educação formal e que migraram em grande fluxo a centros urbanos. Sem entrar em critérios de qualidade, a midiatização da violência, para além de um estigma que a vincula à pobreza ou ao popular, é fruto de uma demanda por visibilidade de grupos social e historicamente marginalizados. Mais que uma técnica, o meio de comunicação se consolidou como uma "forma cultural" (WILLIAMS, 2016), um lugar onde se manifestam as experiências cotidianas. Nessa interpretação, o ato de produzir ou consumir televisão tem relação intrinseca com as dinâmicas da vida social, pois "o espaço televisivo não existe paralelamente às nossas experiências, mas é uma delas - com um fortíssimo poder de penetração nos demais âmbitos de nossa vivência" (FRANÇA, 2006, p. 33).

Para entender o papel do testemunho na construção narrativa de personagens em noticiários criminais, a argumentação parte de uma discussão teórica sobre testemunho, técnica social ligada ao estatuto da confissão e que ganhou novas dimensões em sociedades midiatizadas. Em seguida, há a descrição dos procedimentos metodológicos de uma análise de conteúdo de 80 edições de dois noticiários, o Balanço Geral e o Tribuna da Massa (outubro a dezembro de 2017), veiculados em Curitiba (PR), e de um estudo de recepção com 18 telespectadores desses programas (setembro de 2018).

$\mathrm{Na}$ análise, observa-se que a midiatização da violência no Brasil é pautada pela legitimação de determinadas formas de violência - como a policial e a da justiça pelas próprias mãos -, e pela naturalização de formas de preconceito que, paradoxalmente, vislumbram extirpar a delinquência por meio da estigmatização da representação social marginal. Nessa linha o papel do testemunho possui certa singularidade. O uso de dispositivos de vigilância e de várias categorias de personagens, inclusive a partir da personificação das fontes oficiais, se sobressai. Além disso, a incorporação de um tipo particular de personagem merece destaque: o familiar. Sem ser vítima, agressor ou testemunha ocular, ele participa da narrativa com o intuito de caracterizar as vitimas e agressores, o que reforça um processo de estigmatização nas narrativas audiovisuais.

\section{Dimensões da confissão e do testemunho}

Com a modernidade, a palavra confissão sofreu uma alteração etimológica. De "garantia de status, de identidade e de valor atribuido a alguém por outrem, passou-se à 'confissão' como reconhecimento, por alguém, de suas próprias ações ou pensamentos" (FOUCAULT, 2015, p. 65, grito do autor). O termo se tornou tão ubíquo que as sociedades ocidentais o naturalizaram, a ponto de ser improvável avaliar como essa forma de poder é confrontada com as subjetividades das pessoas.

A relação entre jornalismo e confissão, estruturada pela lógica do testemunho, possui traços particulares que ratificam a atividade como um dispositivo notável de estigmatização. Ao se tornar socialmente conhecido, um indivíduo tem sua biografia reduzida a uma "seleção de fatos sobre ele que podem ser verdadeiros e que se expandem até adquirir uma aparência dramática e digna de atenção, sendo, posteriormente, usados como um retrato global" (GOFFMAN, 2008, p. 82). Se uma exibição pode resumir uma biografia, a estigmatização individual não é a única implica- 
ção quando se pensa no estatuto da confissão.

No âmbito da recepção, o público, embora na maioria das vezes esqueça pontos objetivos das notícias, é competente para identificar matrizes narrativas que, de certa forma, preenchem os vazios semânticos (ANDRÉ, 2018). Essas bases - vinculadas a instituições como família, igreja, espaço geográfico e mundo do trabalho - são áreas de manipulação de estigmas. Por isso, pessoas que partilham atributos físicos e/ou sociais das vítimas e agressores são, por intermédio da estigmatização, invisibilizadas.

Dessa forma, as narrativas jornalisticas, para além de uma técnica textual, devem ser estudadas a partir do modo e da finalidade com que são produzidas ao longo do tempo, tanto para a fonte que sai do anonimato para participar de um evento noticioso quanto para a audiência. Nas notícias criminais, especificamente, há necessidade de descrever pormenores dos atos de violência, de incrementar frases de efeito do agressor contra valores vigentes e instituições hegemônicas, de adjetivar para sobrepor emoções aos fatos e de atenuar contradições ao ofuscar ambivalências. Esses aspectos se dão por processos de identificação que "'convidam' o leitor a vivenciar os eventos como uma testemunha mediada"2 (VAN KRIEKEN; HOEKEN; SANDERS, 2015, p. 2, tradução nossa).

A narrativa criminal atribui na construção de personagens elementos que dialogam com a ficção, não avaliada como sinônimo de mentira, e sim como um recurso que preenche os vazios semânticos das histórias na recepção. Afinal, um texto, mesmo o imagético, jamais desenvolverá todas as "propriedades de um individuo ou coisa, porque de modo algum um mundo narrativo pode ser totalmente autônomo do mundo de referência" (JÁCOME, 2013, p. 185). Assim, a ficção é formada por uma matriz narrativa que contém: uma história, enredo no qual se desenvolvem ações dramáticas; personagens, os tipos que vivenciam conflitos até o desfecho da história; e espaços e tempos, que representam o cenário e o contexto a partir dos quais se define a fixação realista da história (REUTER, 2007). O conjunto desses elementos faz com que a ficção seja credivel e estabeleça diálogos com o mundo de referência.

A matriz narrativa das notícias sobre crimes segue lógica similar, embora, em oposição ao narrador literário, um jornalista se ancore em fatos cujas versões são construidas por uma complexa rotina produtiva que vai da apuração à circulação. Para que os dados das histórias ganhem sentido na recepção, "um jornalista seria forçosamente levado a explorar as similaridades metafóricas entre os conjuntos de acontecimentos reais e as estruturas de ficção" (CASADEI, 2010, p. 85).

A força metonímica adquirida por ocorrências singulares reduz as biografias dos individuos aos fatos expostos na notícia, o que pode selar um "destino" norteado pela estigmatização. Os vínculos entre fato e ficção na exposição de personagens, além de provocarem indagações acerca do campo profissional enquanto instituição que busca e é pautada pela verdade, auxiliam para a compreensão de como se formam os estereótipos. A previsibilidade decorre das descrições do personagem e de suas atitudes, além do tempo e espaço onde ele vivenciou a ação dramática. Nesse contexto ganha relevância o testemunho. As intepretações mais atuais do termo, aliás, o aproximam dos noticiários criminais. O predicado que o coloca como fruto de uma situação trágica ou, no mínimo, de tensão, indica que esse mecanismo é elaborado por quem presencia ou sobrevive a determinado acontecimento (CUNHA, 2012; PERES, 2016) e, como indica este estudo, por quem, externo ao evento, é familiar, especialmente da vítima.

A técnica fortaleceu-se como uma das principais para a formação de um ideal de comunidade, à medida que proporcionou prestígio a quem auxilia no avanço de uma investigação, no desfecho de um crime ou situação de tensão. Por receio da invisibilidade social - entendida como uma espécie de "morte simbólica" (ATHAYDE; BILL; SOARES, 2005) que ocorre a partir de uma 
realidade preestabelecida por estereótipos -, as pessoas assumem um compromisso moral ao se colocarem, se convocadas, como testemunhas.

A ação dialoga ainda com princípios da "cultura da participação", resumida à flexibilidade que as pessoas têm para produzir bens simbólicos e/ ou materiais de forma voluntária (SHIRKY, 2011). Esse elo social não se consolida porque se diz algo em frente às câmeras, e sim porque só se produz sentidos aos relatos nas mediações: pessoas que se envolvem emotivamente com um crime hediondo midiatizado e que conversam entre si sobre o assunto; que delatam um foragido representado em retrato-falado ou por denúncia anônima; que formam conselhos de segurança. Nessa ordem, elas partilham medos e expectativas; participam simbolicamente de atos conjuntos em torno de uma ideia de justiça; e formulam, enfim, um posicionamento público com vistas a protagonizar transformações sociais. Em sintese, testemunham sentimentos e visões de mundo a partir da mídia e, por extensão, alimentam uma dinâmica para que exista uma lógica de testemunho na própria mídia (FROSH; PINCHEVSKI, 2008).

$\mathrm{Na}$ esteira das questões de colaboração e participação social, Sennett (2003) alerta que o testemunho é uma forma de as pessoas demonstrarem que são dignas de confiança, sobretudo em situações nas quais um semelhante está em dificuldade. Sodré (2012) lembra que a possibilidade de relatar um acontecimento notório proporciona o acesso à visibilidade, ao direito a narrar uma história. Como as narrativas criminais são pautadas pelo princípio de que a violência será extirpada com o fim dos malfeitores, o que explica até certo ponto a apologia a discursos ostensivos, os testemunhos ratificam a noção de que a sociedade vive um embate permanente entre bem e mal, com prevalecimento do último. A técnica, nessas condições, adquire uma conduta moralizante, algo que ajuda a explicar a razão pela qual os noticiários criminais sustentam principios de conservadorismo e intolerância. Por fim, Das (2011) vincula o testemunho a aspectos psicológicos, à medida que o ato, especialmente quando realizado por uma vitima ou testemunha ocular, estabelece uma ponte entre o acontecimento e a própria subjetividade desse interlocutor. Testemunhar, por esse ângulo, seria reconhecer a si próprio.

É inimaginável propor um modelo de jornalismo sem o uso do testemunho. Uma das propriedades mais relevantes da técnica é ser um recurso de visibilidade (CUNHA, 2012). Espaço no qual se notabiliza a fonte do tipo personagem, o dispositivo serve para apresentar versões sobre fatos aos quais se deseja transformar em notícia e, não obstante, para construir personagens. As discussões sobre personagens no jornalismo foram escamoteadas devido à hegemonia da ideologia da objetividade. O jargão costuma ser reduzido ao encontro de uma fonte que referende uma verdade presumida pela proposta de pauta (CASADEI, 2010; PERES, 2016), o que favorece a estigmatização. Porém, não significa que esses personagens, ainda que estereotipados na produção, sejam irrelevantes em narrativas que ganham, efetivamente, sentidos nas mediações. É nessa linha argumentativa que a análise, apresentada após procedimentos metodológicos, se sustenta.

\section{Procedimentos metodológicos, noticiários e público}

Desdobrado da tese do autor (ANDRÉ, 2018), o estudo contemplou duas fases conjugadas. Primeiro foi realizada uma análise de conteúdo de 80 edições dos noticiários Balanço Geral e Tribuna da Massa, de outubro a dezembro de 2017 (950 inserções noticiosas). O objetivo foi entender a construção de personagens na narrativa criminal, levando em conta categorias como região geográfica, faixa etária, gênero, além dos tipos de fontes que participam dos programas - para este artigo foram usados apenas os dados referentes às fontes consultadas pelos noticiários.

Depois foi produzido um estudo de recepção com 18 telespectadores (setembro de 2018). O grupo é formado por pessoas que habitam uma das três regiões onde houve maior incidência de crimes exibidos na primeira fase: os municipios metropolitanos São José dos Pinhais (SJP) e Colombo (COL), onde houve a maior incidência de 
crimes, respectivamente, no Balanço Geral e no Tribuna da Massa, além da Cidade Industrial de Curitiba (CIC), bairro que agregou o maior número de crimes veiculados pelos dois noticiários na capital. O objetivo do estudo de recepção, elaborado a partir de entrevistas em profundidade (que somam 20 horas), foi entender como são as apropriações dos telejornais na vida cotidiana dos telespectadores.

A análise de conteúdo é um método capaz de identificar construções simbólicas e estratégias narrativas (HERSCOVITZ, 2010). Já a entrevista, a mais flexivel técnica de coleta de dados (GIL, 1999), tem potencial para a "compreensão detaIhada das crenças, atitudes, valores e motivações, em relação aos comportamentos das pessoas em contextos sociais especificos" (GASKELL, 2002, p. 65). Nela, um pesquisador, ainda que com objetivos pré-definidos, pode estabelecer novos recortes a partir dos dados coletados. Para o escopo deste estudo houve a seleção especifica de pontos nos quais os entrevistados tratavam das representações sociais de pessoas/personagens que participam dos noticiários, sobretudo vítimas, agressores e forças policiais (já as características das tecnologias de vigilância não foram exploradas diretamente nas entrevistas originais).

Para entender os usos das fontes pelos programas e as apropriações pelo público é preciso citar, suscintamente, caracteristicas dos telejornais, consumidos diariamente em mais de 150 mil residências de Curitiba e Região Metropolitana (O CANAL, 2017), e cujas audiências oscilam entre a segunda e terceira colocações no horário do almoço. O Balanço Geral, veiculado desde 2008, é exibido entre meio-dia e 14h25 pela RICTV (Rede Record). Na época da análise era apresentado por Gilberto Ribeiro, que trabalhava em rádio e televisão havia mais de 30 anos. Já o Tribuna da Massa, criado em 2001, é o mais antigo noticiário criminal em exibição na região. Transmitido pela Rede Massa (SBT), entre 11h45 e 14hoo, é ancorado desde setembro de 2017 por Eleandro Passaia.

Com versões locais exibidas pelas afiliadas da Record em todos os estados, o Balanço Geral é um dos principais produtos informativos do grupo, a ponto de criar uma ideia de "regionalização padronizada", propriedade também visivel em nivel estadual no Tribuna da Massa. Os dois telejornais carregam como marca registrada a "personalização", uma tentativa de se diferenciar dos concorrentes mais consolidados mediante a centralidade do apresentador (HAMILTON, 2008). Isso não significa que tais atrações não buscam estreitar vínculos com os telejornais de referência. O tratamento narrativo passa por uma redução de imagens apelativas, embora juízos de valor permaneçam (ANDRÉ, 2021). Vitimas e agressores são vinculados e desvinculados a questões caras à audiência, como a familia de padrão heteronormativo, a moral do trabalho, a religião de matriz cristã e, por extensão, a legitimação à brutalidade policial.

Embora o Balanço Geral seja o único a disponibilizar o perfil do público, é possivel inferir, quando se consideram temática, horário de exibição e publicidade, que a audiência presumida pelo Tribuna da Massa seja similar. Os dados apontam que $25 \%$ da audiência tem entre 50 e 59 anos, e $36 \%$ acima de 60 anos (RICTV, 2018). Em relação ao recorte por classe, é voltado majoritariamente à classe C (51\% da audiência), cuja renda varia entre dois e quatro salários-mínimos (PILLI, 2019).

O Quadro 1 reúne as principais características socioeconômicas, bem como os vínculos dos participantes com os programas. 
Quadro 1 - Perfil socioeconômico e de consumo dos noticiários Balanço Geral e Tribuna da Massa

\begin{tabular}{|c|c|c|}
\hline Gênero & $\begin{array}{l}\text { Masculino } \\
\text { Feminino }\end{array}$ & $\begin{array}{l}\mathrm{ClC}_{1}, \mathrm{ClC}_{3}, \mathrm{ClC} 4, \mathrm{ClC6}, \mathrm{COL} 2, \mathrm{COL} 5, \mathrm{SJP} 2, \mathrm{SJP} 4, \mathrm{SJP} 5 \\
\mathrm{ClC}_{2}, \mathrm{ClC}_{5}, \mathrm{COL} 1, \mathrm{COL} 3, \mathrm{COL} 4, \mathrm{COL} 6, \mathrm{SJP} 1, \mathrm{SJP} 3, \mathrm{SJP} 6\end{array}$ \\
\hline Faixa etária & $\begin{array}{l}18 \text { e } 29 \text { anos } \\
30 \text { e } 39 \text { anos } \\
40 \text { a } 49 \text { anos } \\
50 \text { a } 59 \text { anos } \\
\text { Acima de } 60 \text { anos }\end{array}$ & $\begin{array}{l}\text { COL5, SJP3, SJP4 } \\
\text { SJP1, SJP5 } \\
\text { ClC4, CIC6, COL3 } \\
\text { CIC2, CIC5, COL1, SJP2, SJP6 } \\
\text { ClC1, ClC3, COL2, COL4, COL6 }\end{array}$ \\
\hline $\begin{array}{l}\text { Grau de } \\
\text { instrução }\end{array}$ & $\begin{array}{l}\text { Ensino fundamental } \\
\text { Ensino médio } \\
\text { Ensino superior }\end{array}$ & $\begin{array}{l}\mathrm{ClC}_{1}, \mathrm{ClC}_{3}, \mathrm{ClC} 5, \mathrm{COL} 1, \mathrm{COL} 2, \mathrm{COL} 3, \mathrm{COL} 4, \mathrm{COL} 5, \mathrm{SJP} 1, \mathrm{SJP} 2 \\
\text { SJP6 } \\
\mathrm{ClC}_{2}, \mathrm{ClC} 4, \mathrm{ClC} 6, \mathrm{COL} 6, \mathrm{SJP} 5 \\
\text { SJP3, SJP4 }\end{array}$ \\
\hline $\begin{array}{l}\text { Renda (salá- } \\
\text { rio-mínimo) }\end{array}$ & $\begin{array}{l}\text { Sem renda fixa } \\
\text { Até dois salários } \\
\text { De dois a quatro salários } \\
\text { Acima de cinco salários }\end{array}$ & $\begin{array}{l}\mathrm{ClC}_{4}, \mathrm{SJP} 1 \\
\mathrm{ClC}_{3}, \mathrm{COL} 1, \mathrm{COL} 2, \mathrm{COL} 5, \mathrm{COL6}, \mathrm{SJP} 4 \\
\mathrm{ClC} 2, \mathrm{CIC} 5, \mathrm{COL} 4, \mathrm{SJP} 2, \mathrm{SJP} 3, \mathrm{SJP} 6 \\
\mathrm{ClC}_{1}, \mathrm{COL} 3, \mathrm{ClC} 6, \mathrm{SJP} 5\end{array}$ \\
\hline $\begin{array}{l}\text { Vínculo em- } \\
\text { pregatício }\end{array}$ & $\begin{array}{l}\text { Desempregado } \\
\text { Aposentado } \\
\text { Pensionista } \\
\text { Mercado formal } \\
\text { Mercado informal }\end{array}$ & $\begin{array}{l}\mathrm{ClC}_{4}, \mathrm{COL} 3, \mathrm{SJP} 1, \mathrm{SJP} 3 \\
\mathrm{ClC}_{1}, \mathrm{ClC}_{3}, \mathrm{COL} 2, \mathrm{COL} 6 \\
\mathrm{ClC}_{2}, \mathrm{CIC} 5, \mathrm{COL} 1, \mathrm{COL} 4 \\
\text { COL5, SJP2, SJP4, SJP5, SJP6 } \\
\text { ClC6 }\end{array}$ \\
\hline $\begin{array}{l}\text { Consumo } \\
\text { semanal }\end{array}$ & $\begin{array}{l}\text { Diário } \\
\text { Mais de três vezes } \\
\text { Ocasional }\end{array}$ & $\begin{array}{l}\mathrm{ClC}_{1}, \mathrm{ClC}_{3}, \mathrm{ClC} 5, \mathrm{COL} 1, \mathrm{COL} 4, \mathrm{COL6}, \mathrm{SJP} 1 \\
\mathrm{ClC}_{4}, \mathrm{ClC} 6, \mathrm{COL} 2, \mathrm{COL} 3, \mathrm{COL} 5, \mathrm{SJP} 2, \mathrm{SJP} 3, \mathrm{SJP} 4, \mathrm{SJP} 5, \mathrm{SJP} 6 \\
\mathrm{ClC}_{2}\end{array}$ \\
\hline $\begin{array}{l}\text { Tempo de } \\
\text { consumo } \\
\text { por edição }\end{array}$ & $\begin{array}{l}\text { Até } 30 \text { minutos } \\
\text { Até uma hora } \\
\text { Mais de uma hora }\end{array}$ & $\begin{array}{l}\text { ClC2, SJP3 } \\
\text { ClC5, SJP1, SJP4 } \\
\mathrm{ClC}_{1}, \mathrm{ClC}_{3}, \mathrm{CIC} 4, \mathrm{CIC6}, \mathrm{COL} 1, \mathrm{COL} 2, \mathrm{COL} 3, \mathrm{COL} 4, \mathrm{COL} 5, \mathrm{COL} 6, \\
\text { SJP2, SJP5, SJP6. }\end{array}$ \\
\hline $\begin{array}{l}\text { Tempo de } \\
\text { consumo }\end{array}$ & $\begin{array}{l}\text { Até dois anos } \\
\text { Entre dois e cinco anos } \\
\text { Entre cinco e dez anos } \\
\text { Acima de dez anos }\end{array}$ & $\begin{array}{l}\mathrm{COL} 5 \\
\mathrm{ClC}_{4}, \mathrm{ClC} 6, \mathrm{COL} 3, \mathrm{SJP}_{3}, \mathrm{SJP} 4, \mathrm{SJP} 6 \\
\mathrm{ClC}_{5}, \mathrm{COL} 6, \mathrm{SJP} 5 \\
\mathrm{ClC}_{1}, \mathrm{ClC} 2, \mathrm{ClC}_{3}, \mathrm{COL} 1, \mathrm{COL} 2, \mathrm{COL} 4, \mathrm{SJP} 1, \mathrm{SJP} 2\end{array}$ \\
\hline
\end{tabular}

Fonte: André (2018).

Os entrevistados, divididos igualmente entre homens e mulheres, a maioria acima dos 50 anos, em conformidade com o perfil hegemônico da audiência presumida. No quesito renda familiar, dois terços recebem até quatro salários mínimos. Apenas dois cursaram ou cursaram o ensino supe- 
rior, enquanto a maioria estudou, no máximo, até o fim do Ensino Fundamental. A maioria perde, no máximo, uma ou duas edições semanais. O nivel de engajamento é alto: dois terços dos participantes consome as edições por mais de uma hora e quase metade tem o hábito de acompanhar os programas há mais de uma década.

\section{Personagens em notícias criminais}

O uso de testemunhos é habitual no jornalismo por sua ligação com o estatuto da confissão, dinâmica social pautada pelas relações entre saber e poder que legitima a abordagem pública dos temas. Nos programas estudados, as notícias se apropriam desse recurso por conta de construções narrativas que reforçam um clima de tensão potencializado pelos testemunhos em off. Em 15\% das quase 800 inserções que possuiam, no mínimo, uma fonte, elas aparecem em condição de anonimato. No gênero reportagem, a proporção de fontes anônimas é de uma a cada cinco (Balanço Geral) e uma a cada três (Tribuna da Massa). O teor testemunhal confrontado com as percepções do público sobre as histórias permite a observação de três características constantes nessas narrativas: a personificação das fontes oficiais, a substituição de testemunhas oculares por tecnologias de vigilância e a apropriação de familiares que, apesar de não serem vítimas, agressores ou terem presenciado o crime, são entrevistados quase sempre devido a laços afetivos com vítimas ou agressores.

\section{Personificação das fontes oficiais, tecnologias de vigilância e testemunhas oculares}

Além dos eventos em que são vítimas, agressores ou testemunhas oculares, os agentes policiais, representação hegemônica das fontes oficiais (na análise de conteúdo, 41,6\% das fontes consultadas pelo Balanço Geral e 29,0\% pelo Tribuna da Massa pertencem à categoria), aparecem principalmente como interlocutores. A personificação sugere um ideal romantizado da atividade, presente nas percepções que os entrevistados têm sobre a relevância de midiatizar os esforços da polícia, instituição que, para eles, possui uma estrutura de trabalho precária e é inibida de exercer um papel mais ostensivo, saida considerada mais efetiva para a solução dos problemas de segurança pública.

De modo regular, os participantes não lembram de notícias exibidas pelos telejornais, mesmo aquelas nas quais julgam que a polícia agiu bem. Apenas três frisam que a instituição é corrompida e/ou que possui estrutura precária a ponto de interferir nos resultados das ações (ClC4, SJP3, SJP5). O chaveiro $\mathrm{ClC}_{4}, 47$ anos, diz não aceitar o fato de policiais cometerem injustiças para além do âmbito individual, enquanto a zeladora CIC5, 58 anos, divide-se sobre o tema. Os demais avaliam que a instituição exerce bem seu papel na maioria das histórias exibidas pelos noticiários: falta de recursos, rigor no exame sobre as condutas dos agentes e impunidade no sistema judicial ocasionada pela burocracia das investigações são problemas narrados pelos noticiários que a corporação, segundo esses entrevistados, resiste até com certa bravura.

Essas apreensões produzem um sentido comum: os participantes condenam, por um lado, erros da polícia, ressaltados como fruto de ações pessoais ( $\mathrm{ClC}_{1}, \mathrm{ClC}_{2}, \mathrm{ClC}_{3}, \mathrm{COL} 2, \mathrm{COL} 4, \mathrm{SJP} 1$, SJP4, SJP6) - tipo de representação social que Moscovici (2015) vincula ao espectro político mais conservador -, mas naturalizam com transparência as práticas ostensivas. A pensionista COL1, 51 anos, foi uma das poucas a se recordar de um caso exibido pelos telejornais. Questionada sobre porque considerou como correta uma ação que resultou em morte, diz que "vagabundo tem que morrer mesmo" (COL1, informação verbal3). Já o técnico-eletricista SJP4, 29 anos, defende que a corporação deva ter permissão para agir ostensivamente. "Não considero isso como violência. A forma como o bandido aborda é violenta, a forma como ele entra numa casa, como ele faz

\footnotetext{
3 Depoimento concedido ao autor, na cidade de Colombo, PR, Brasil, no dia 21 de setembro de 2018. Todos os entrevistados serão tratados de forma anônima e serão diferenciados a partir das iniciais da região geográfica as quais pertencem.
} 
o refém, é violenta" (SJP4, informação verbal4). Na fase de análise de conteúdo, cerca de 10\% das inserções monitoradas do Tribuna da Massa fazem apologia explícita à repressão violenta contra a categoria bandido, número que cai pela metade no Balanço Geral. Embora o número pareça baixo, implicitamente a apologia é recorrente, algo que encontra consonância com as representações sociais construidas pelo público.

Perguntado sobre quando vê nos programas situações de conflitos que envolvem policiais, o agente de escolta armada ClC6, 40 anos, é efusivo ao defender que a sociedade precisa temer a polícia e que há "bom trabalho" em operações que culminam em morte: "Tem que bater parabéns para a polícia. A polícia tem que mostrar o trabalho dela e ser respeitada" (CIC6, informação verbal5). Na mesma linha, o vigilante SJP2, 51 anos, gosta de ver notícias sobre "arrastões", perseguições policiais. "Quando fazem isso, eles dão uma segurança para o pessoal de bem" (informação verbal ${ }^{6}$ ). Se a costureira COL4, 57 anos, é solidária ao afirmar que os agentes sofrem, o funileiro COL5, 22 anos, ressalta o quanto há "pouca polícia" (informação verbal7). Já a contadora aposentada COL6, 67 anos, soma à noção de pouco policiamento o fato de o sistema judicial se opor à corporação, argumento usado permanentemente nos dois programas estudados: "A polícia perde muito tempo em cima de um caso - a justiça, a lei, em geral - que é óbvio, que não tem o que investigar" (COL6, informação verbal $\left.^{8}\right)$. Na mesma toada, mas de forma mais incisiva, a encarregada desempregada COL3, 48 anos, questiona o tratamento, segundo ela, desproporcional recebido por policiais que cometem crimes: "Por que o ladrão arruma advogado rapidinho e a polícia não?" (informação verbal9).

O espaço cedido a fontes oficiais prevalece no jornalismo criminal. $O$ ato de um policial ser entrevistado, a princípio, seria tangenciado por informações que explicassem a investigação. Com exceção uma reportagem sobre o aumento das prisões de homicidas em Curitiba (POLíCIA .... 2017) nas demais há sobreposição da descrição de pormenores do crime, com ênfase para as ações dos agentes, ou, no máximo, do histórico criminal da vítima, redundância informativa que costuma ocorrer nas passagens, offs e comentários dos âncoras. Os detalhes da ação criminosa costumam ser terceirizados à polícia, o que justifica a aparição desproporcional em relação aos demais tipos de fontes, bem como parte relevante dos sentidos despertados no público.

As especificidades das histórias têm exposto vitimas e agressores de forma genuina com as tecnologias de vigilância. Essas tecnologias reconfiguram a testemunha ocular, a fonte que presencia com relativa proximidade ou condição favorável um fato que envolveu terceiro. Na recepção, essa estrutura narrativa ganha sentidos ao reiterar o princípio da testemunha mediada (VAN KRIEKEN; HOEKEN; SANDERS, 2015), já que esse dispositivo permite que os próprios telespectadores testemunhem os acontecimentos repetidas vezes. Embora nas entrevistas originais não tenha havido uma preocupação em avaliar o papel das tecnologias de vigilância, é possivel pinçar alguns fragmentos que reiteram a importância das câmeras de vigilância no relato de casos antes, durante ou depois de um crime (COL3, COL4). Com exceção de dois entrevistados que tocaram no assunto (COL5, SJP6), para os demais as imagens servem para mostrar - testemunhar - a realidade e, assim, cobrar por justiça.

Interpretadas como indices do real, tais imagens transformam em notícia, além dos crimes graves, delitos que antes do advento desses dispositivos não teriam visibilidade. Os exemplos mais usuais extraídos da análise de conteúdo são de furtos de pequenas mercadorias, geralmente alimentícias. Além delas, excluidos os latrocínios

\footnotetext{
Depoimento concedido ao autor, na cidade de São José dos Pinhais, PR, Brasil, no dia 24 de setembro de 2018 Depoimento concedido ao autor, na cidade de Curitiba, PR, Brasil, no dia 24 de setembro de 2018.

Depoimento concedido ao autor, na cidade de São José dos Pinhais, PR, Brasil, no dia 15 de setembro de 2018.

Depoimento concedido ao autor, na cidade de Colombo, PR, Brasil, no dia 21 de setembro de 2018.

Depoimento concedido ao autor, na cidade de Colombo, PR, Brasil, no dia 26 de setembro de 2018.

Depoimento concedido ao autor, na cidade de Colombo, PR, Brasil, no dia 26 de setembro de 2018.
} 
e os crimes com ações de perseguição policial, observa-se nos roubos, o uso recorrente dessas tecnologias. Elas aparecem próximas da metade das inserções no Balanço Geral (45,8\%) e no Tribuna da Massa (54,3\%) que contenham, no mínimo, uma fonte. O uso se aplica na exibição de flagrantes, algo consonante à lógica de descrição de pormenores dos crimes: no Balanço Geral, uma a cada três peças contém apenas a tecnologia de vigilância como fonte; no Tribuna da Massa, uma a cada quatro. São todas de flagrantes e com narrativas que versam sobre o grau de perversidade do criminoso, seja por ações desproporcionais de violência, por atacar instituições filantrópicas, ou ainda, pela criatividade ou ousadia do criminoso ou da vítima.

\section{Vítimas, agressores e familiares}

A despeito da representatividade da fonte oficial personificada e das tecnologias de vigilância, agressores e vítimas são, qualitativamente, os tipos centrais de fontes quando se pensa na recepção, já que todo crime midiatizado envolve, necessariamente, esses dois tipos. Excetuados os atos de violência restritos ao que os produtores intitulam como "universo do crime", o perfil das vitimas costuma ser vinculado à moral da família, ao mundo do trabalho e à concepção cristã de religião (ANDRÉ, 2018), enquanto os agressores são dissociados dessas instituições. Nas 80 edições estudadas, uma a cada dez inserções envolve notícias nas quais vitimas e agressores integram um mesmo núcleo parental. Diálogos com a noção de familia, contudo, são regulares, de modo que quanto mais há aproximações dessa instituição, mais aumentam as chances de exibição.

Essa forma de narrar as histórias tem estreita relação com as percepções do público, algo visto em três tipos de fontes usados pelos noticiários: vitima, agressor e familiar. O fato de não memorizar aspectos objetivos das notícias não impede que sentidos sejam produzidos, o que corrobora a matriz sob a qual os crimes são narrados como estruturante. Os participantes mencionam situações genéricas com as quais se acostumaram a ver violência na televisão. Narrativas que envolvam a instituição familia foram citadas direta e espontaneamente por mais de dois terços dos entrevistados.

As citações sobre familia independem da recordação das notícias. "É o pai que mata o filho, é a filha que mata a mãe, é o neto que mata a avó para pegar dinheiro", diz o carpinteiro aposentado $\mathrm{ClC}_{3}, 67$ anos, sem saber especificar algum ato veiculado nos telejornais $\left(\mathrm{ClC}_{3}\right.$, informação verbal $\left.^{10}\right)$. Favorável a políticas de armamento da sociedade civil, o policial militar aposentado ClC1, 60 anos, vincula o problema da impunidade aos direitos humanos que, na visão dele, contraria a concepção familiar: "Pai de familia morre, direitos humanos não vai lá na casa dele, mas se um policial matar um sem-vergonha desse ai em ponta da esquina..." (CIC1, informação verbal $\left.{ }^{11}\right)$. A dona de casa e pensionista CIC2, 53 anos, justifica a apologia a reações ostensivas ao dizer que é melhor ver um criminoso "morrer do que ele matar um parente" (ClC2, informação verbal $\left.{ }^{12}\right)$. Por isso, ela, que credita à família do agressor responsabilidade solidária pelo crime, critica medidas de ressocialização. "O criminoso vai para a cadeia e tem um dinheirão lá para dar para a familia, enquanto tem gente aí que trabalha, não ganha aquilo que eles ganham, está morrendo de fome, não tem onde morar". Em oposição, o caminhoneiro aposentado COL2, 66 anos, usa a lógica familiar para ser empático.

O exemplo dado pelo metalúrgico SJP5, 39 anos, reforça a admiração que ele sente pelos produtores que, na visão dele, estão do lado das pessoas mais vulneráveis. Ele se recorda do caso de uma mulher assassinada para reforçar como a violência urbana é uma grande ameaça à instituição familia. A construção ganha conotação maniqueísta justamente pelo fato da utilização da família da vítima, algo que produz sentidos na vida cotidiana do participante: "Entrevistaram a familia, uma casa extremamente humilde. IA

\footnotetext{
Depoimento concedido ao autor, na cidade de Curitiba, PR, Brasil, no dia $1^{\circ}$ de setembro de 2018.

Depoimento concedido ao autor, na cidade de Curitiba, PR, Brasil, no dia $1^{\circ}$ de setembro de 2018.

Depoimento concedido ao autor, na cidade de Curitiba, PR, Brasil, no dia $1^{\circ}$ de setembro de 2018.
} 
história] me marcou bastante também por isso" (SJP5, informação verbal' ${ }^{13}$ ). A zeladora $\mathrm{ClC}_{5}, 58$ anos, também acredita que esses noticiários escolheram o lado dos mais vulneráveis, tornando a realidade das comunidades periféricas mais visibilizada. "A gente é meio abandonado", explica ao falar sobre as dificuldades que os telejornais de referência têm para visibilizar as áreas periféricas: "Aí comecei a me interessar porque vi que eles estavam defendendo o povo. Eu estava sendo representada" (CIC5, informação verbal $\left.{ }^{14}\right)$.

A auxiliar de limpeza SJP6, 59 anos, vincula violência à tragédia familiar ao se recordar de homicídios contra crianças e idosos. Ela diz sofrer com o uso de imagens que explorem o sofrimento materno: "Ali [na transmissão] o filho já morreu. Eu me coloco muito no lugar da mãe, no sofrimento que a mãe vai ter dali pra frente" (SJP6, informação verbal ${ }^{15}$ ). A cabelereira SJP1, 34 anos, também se identifica com a figura materna quando cita um caso de homicídio veiculado no Balanço Geral, envolvendo uma pessoa que ela já havia visto presencialmente: "Fiquei pensando na mãe, porque me recordo dela. No dia que passou a entrevista deu para ver a mãe indo ver o corpo" (SJP1, informação verbal ${ }^{16}$ ).

Com base na relevância que a instituição família tem no imaginário do público, os três últimos tipos de fontes têm relação - por complemento ou dissociação - dessa instituição. Em um contexto de valorização da vida, a vítima, a pessoa que relata atos de violência vividos na pele, tem papel fundamental nos processos de identificação. Essa categoria é protagonista quando o assunto é violência, já que o testemunho da vítima marca como o "discurso sobre a violência se volta para o sujeito que a sofreu, a partir de uma noção afirmativa desse sujeito como um sujeito de direitos" (SARTI, 2014, p. 82).

Por estar vinculado ao estatuto da confissão de forma mais direta, o relato do agressor possibilita um leque de abertura para manifestação da moral vigente, seja pelo teor de deboche, que o desvincula da racionalidade, pela reação de arrependimento ou mesmo da argumentação de inocência. Conforme os dados da análise de conteúdo, essa fonte é a que menos costuma ser consultada (incidência de $6 \%$ nos dois noticiários), mas quando aparece é a mais exposta (em apenas $12 \%$ das vezes, em ambos os programas, a condição de anonimato foi respeitada). Isso se deve, basicamente, a três pontos: a) de 75\% (Balanço Geral) a 80\% (Tribuna da Massa) das narrativas, o enfoque está no crime em si, e não nas investigações; b) exibição do rosto acontece independentemente da vontade da pessoa, ação consolidada na produção que fere o princípio da presunção de inocência; e c) a figura social do agressor é que causa mais repulsa na recepção.

A categorização de personagem mais singular das narrativas criminais é, contudo, o familiar, cuja incidência de representação nos telejornais é duas vezes maior que a dos agressores e pouco menos da metade que a das fontes oficiais. $\mathrm{Na}$ maior parte das vezes consultada na cobertura de crimes que resultam em morte, esse tipo contempla personagens que não presenciaram o crime, mas, devido a laços com vítimas ou agressores são entrevistados quase sempre a partir de elementos que estavam vinculados à dramatização ou à recuperação de aspectos de fundamentos morais - da vida pregressa dos envolvidos no ato de violência. Trata-se de uma característica imersa na prática profissional de cobertura de crimes que valoriza, sobremaneira, a lógica de destruição familiar. São depoimentos recolhidos na maior parte das vezes durante funerais ou em cenas de crime, geralmente quando há aglomeração de pessoas enquanto é aguardada a pericia do local e a retirada da vítima (viva ou morta). São ainda entrevistadas em reportagens feitas nas raras investigações que os telejornais acompanham e podem, como no caso da mulher assassinada citada por SJP5, ser justapostas a outros tipos de personagens (os familiares foram testemunhas oculares). 
Pela incidência de crimes ocorridos no âmbito familiar identificados na análise de conteúdo e pela notoriedade que a instituição ganhou na recepção, observa-se a relevância que esse tipo de personagem tem na construção das narrativas sobre crimes. As apropriações dessas estratégias permitem que muitos dos participantes da pesquisa de recepção minimizem ou até mesmo desprezem quaisquer ações de cunho sensacionalista dos programas e os coloquem como atrações de familia.

\section{Considerações finais}

Personagens em jornalismo carregam particularidades em relação aos textos ficcionais. A profissão está ancorada na premissa da verdade, no equilíbrio de vozes e na promoção de debates pautados pela razão e pela emoção. Permanece em diálogo com o campo das narrativas não realistas, contudo, o fato de que o personagem não pode ser separado do todo da narrativa, o que, no caso do jornalismo, contempla as próprias condições de produção das notícias e as tensões entre a objetividade de um acontecimento e os vazios semânticos dessas histórias preenchidos na recepção.

Ao entender o testemunho como um imperativo consolidado na modernidade por meio do estatuto da confissão, no presente artigo propôs-se um estudo desse dispositivo de confissão em noticiários criminais a partir de um diálogo entre personagens narrativamente construídos pelos telejornais e percepções do público. A personificação das fontes oficiais, as reconfigurações das testemunhas oculares mediante novas tecnologias de vigilância e a ascensão da fonte familiar são centrais para compreender o papel dessa técnica no jornalismo criminal, algo que contribui de forma muito singular para a midiatização da violência no Brasil.

Embora haja um olhar enviesado à produção noticiosa e ao teor moral das noticias, as narrativas criminais precisam ser conhecidas a partir das mediações. Essa abordagem permite que se entenda o que se produz socialmente e, em paralelo, impede uma visão hegemônica de que as apropriações desse tipo de narrativa sejam fruto especifico de alienação, mas sim uma visão do popular (MARTíN-
-BARBERO, 2015), da qual as dimensões da família, trabalho e religião, acima da percepção do ato de gostar de sangue, são tributárias.

Em um contexto de relativização da verdade, que dissolve algumas das fronteiras do jornalismo e de outras instituições, o testemunho nas narrativas criminais, embora busque se aproximar na forma de produtos historicamente hegemônicos, utilize filmagens que exibem a realidade e depoimentos de fontes oficiais, parece, por vezes, recolocar a empiria de lado. A força metonímica que as histórias ganham e - por extensão - a estigmatização são processos importantes para se observar como o testemunho é central nesse tipo de narrativa. Nesse aspecto, destaca-se o anonimato como um recurso singular quando se pensa no campo da recepção. Como o público tende a não se recordar dos pormenores da história, o personagem que não aparece auxilia no preenchimento dos vazios semânticos inerentes a qualquer processo de produção de sentidos.

Por fim, uma apreensão relevante, e que precisa ser fruto de problematização no estatuto deontológico quando o assunto são os usos de personagens, é o fato de que os entrevistados, moradores das regiões onde mais foram midiatizados crimes, veem a exibição da violência nessas localidades como forma de visibilidade. Há um sentido comum observado nas entrevistas de que direitos, especialmente da população carcerária, sejam interpretados como privilégios, algo que se vincula a uma concepção deturpada de cidadania, incapaz de enxergar algumas violações de direitos sofridas pelos próprios entrevistados, e que é alimentada pelas narrativas criminais.

Entende-se que essas características lançam desafios estruturantes não apenas para as formas consideradas mais nobres de jornalismo, que perdem progressivamente confiança junto ao público, mas para o próprio projeto de sociedade que se almeja para as próximas décadas. Ao estudar o diálogo dessas narrativas com a dimensão da recepção, e entendendo que elas emergem características que superam os dois programas estudados aqui, observa-se que as consequências das políticas de modernização 
do país ainda estão em pleno andamento.

Com esses desafios em mente, o jornalismo, enquanto instituição, enfrenta desafios que, necessariamente, passam pelo público para que a área torne a se configurar como um campo proeminente de visibilidade, capaz de contribuir para o fortalecimento da democracia. Em que pensem as muitas violações testemunhadas na análise de conteúdo e refratadas nas entrevistas, entende-se que esses programas constroem densos vínculos com as audiências. Esses vínculos, conforme a pesquisa aponta, estruturam-se mais pela lógica familiar do que pela midiatização da violência em si, característica que, ao contrário de uma concepção positivista de objetividade, pode ser aproveitada tanto pelos próprios noticiários - hoje de veio policialesco - quanto por iniciativas jornalisticas mais vinculadas ao estatuto normativo do campo.

\section{Referências}

ANDRÉ, $H$. "Violência fascinante em vidas tão normais": relações de estigmatização e invisibilidade social na recepção de noticiários criminais. 2018. 528 f. Tese (Doutorado em Jornalismo) - Programa de Pós- Graduação em Jornalismo, Centro de Comunicação e Expressão, Universidade Federal de Santa Catarina, Florianópolis, 2018.

ANDRÉ, H. Quando dilemas viram rotinas: desafios éticos na produção de noticiários criminais. Ação Midiática: Estudos em Comunicação, Sociedade e Cultura, Curitiba, v. 21, p. 177-197, 27 jan. 2021

ATHAYDE, C.; BILL, M. V.; SOARES, L. E. Cabeça de Porco. Rio de Janeiro: Objetiva, 2005.

BRAIT, B. A personagem. 4. ed. São Paulo: Contexto, 2017.

BRASIL. Instituto de Pesquisa Econômica Aplicada (org.). Atlas da Violência. Rio de Janeiro: Ipea, 2018a. 69 p. Disponivel em: https://bit.ly/2PaOjK5. Acesso em: 16 fev. 2021

BRITO, P. R. M. A. A epistemologia do testemunho: visão reducionista. Porto Alegre: PUC, 2012.

CASADEI, E. B. A Construção de Personagens no Jornalismo: entre a matriz de verdade presumida e a imaginação das urdiduras de enredos. C-Legenda, Rio de Janeiro, v. 22, n. 1, p. 77-91, 2010.

COULDRY, N.; HEPP, A. A construção mediada da realidade. São Leopoldo: Ed. Unisinos, 2020.

CUNHA, M. J. A narrativa jornalística em testemunho. In: MOTA, C. L.; MOTTA, L. G.; CUNHA, M. J. (org.). Narrativas midiáticas. Florianópolis: Insular, 2012. p. 117-138.
DAS, V. O ato de testemunhar: Violência, gênero e subjetividade. Cadernos Pagu, Campinas, v. 37, p. 9-41, 2011.

FOUCAULT, M. História da sexualidade: a vontade de saber. 3. ed. São Paulo: Paz e Terra, 2015

FRANÇA, V. A TV, a janela e a rua. In: FRANÇA, V. (org.). Narrativas televisivas: programas populares na TV. Belo Horizonte: Autêntica, 2006. p. 13-45.

FROSH, P.; PINCHEVSKI, A. Media witnessing: Testimony in the age of mass communication. London, England: Palgrave Macmillan UK, 2008.

GASKELL, G. Entrevistas individuais e grupais. In: BAUER, M. W:; GASKELL, G. Pesquisa qualitativa com texto, imagem e som: um manual prático. Petrópolis: Vozes, 2002. p. $64-89$.

GIL, A. C. Métodos e técnicas de pesquisa social. 5 ed. São Paulo: Atlas, 1999.

GOFFMAN, E. Estigma: notas sobre a manipulação da identidade deteriorada. 4. ed. Rio de Janeiro: LTC, 2008.

HAMILTON, F. A. Monitorando telejornais: desafios e perspectivas. In: CHRISTOFOLETTI, R.; MOTTA, L. G. (org.). Observatórios de Midia: olhares de cidadania. São Paulo: Paulus, 2008. p. 95-114.

HERSCOVITZ, H. G. Análise de conteúdo em jornalismo. In: LAGO, C.; BENETTI, M. (org.). Metodologia de pesquisa em jornalismo. 3. ed. Petrópolis: 2010. p. 123-142.

JÁCOME, P. Tensões entre ficção e não ficção no mundo possivel do Jornal Nacional. In: LEAL, B. S.; CARVALHO, C. A. (org.). Narrativas e poéticas midiáticas: estudos e perspectivas. São Paulo: Intermeios, 2013. p. 171-189.

MARTÍN-BARBERO, J. Dos meios às mediações: comunicação, cultura e hegemonia. 7. ed. Rio de Janeiro: Editora UFRJ, 2015

MOSCOVICl, S. Representações sociais: investigações em psicologia social. 11. ed. Petrópolis: Vozes, 2015.

O CANAL. Curitiba: audiências consolidadas, sexta-feira, 29 de dezembro de 2017. Disponivel em: https://bit. ly/38qB6nL. Acesso em: 6 jan. 2021.

ORTIZ, R. A moderna tradição brasileira: cultura brasileira e indústria cultural. 5. ed. São Paulo: Brasiliense, 2001.

PERES, A. C. Narrar o outro: notas sobre a centralidade do testemunho para as narrativas jornalisticas. Galáxia. São Paulo, n. 31, p. 92-104, 2016.

PILLI, L. Critério de classificação econômica Brasil. São Paulo: Associação Brasileira de Empresas de Pesquisa, 2019. Disponivel em: https://bit.ly/3ahopb1. Acesso em: 7 ago. 2020.

POLÍCIA comemora aumento das prisões de homicidas em Curitiba. Tribuna da Massa. Curitiba, ano 16, 29 dez. 2017.

REUTER, Y. A análise da narrativa: o texto, a ficção e a narração. 2. ed. Rio de Janeiro: Difel, 2007. 
RIBEIRO, A. P. G.; SACRAMENTO, I. A renovação estética da TV. In: RIBEIRO, A. P. G.; SACRAMENTO, I.; ROXO, M. (org.). História da televisão no Brasil: do início aos dias de hoje. São Paulo: Contexto, 2010. p. 109-135.

RICTV. Balanço Geral. 2018. Disponivel em: https://bit. ly/2XZQWGK. Acesso em: 6 ago. 2020.

SARTI, C. A construção de figuras da violência: a vitima, a testemunha. Horizontes Antropológicos, Porto Alegre, v. 20, n. 42, p. 77-105, dez. 2014.

SENNETT, R. A corrosão do caráter: as consequências pessoais do trabalho no novo capitalismo. 7. ed. Rio de Janeiro: Zahar, 2003.

SHIRKY, C. A cultura da participação: criatividade e generosidade no mundo conectado. Rio de Janeiro: Zahar, 2011

SODRÉ, M. A narração do fato: notas para uma teoria do acontecimento. 2. ed. Petrópolis: Vozes, 2012.

VAN KRIEKEN, K.; HOEKEN, H.; SANDERS, J. From Reader to Mediated Witness: The Engaging Effects of Journalistic Crime Narratives. Journalism \& mass communication quarterly, Columbia, v. 92, n. 3, p. 580-596, 2015

WILLIAMS, R. Televisão: tecnologia e forma cultural. São Paulo: Boitempo; Belo Horizonte: PUCMinas, 2016.

\section{Hendryo Anderson André}

Doutor em Jornalismo pela Universidade Federal de Santa Catarina (2018), em Florianópolis, SC, Brasil; mestre em Comunicação e Sociedade pela Universidade Federal do Paraná (2012), em Curitiba, PR, Brasil; Professor do curso de Jornalismo da Universidade Federal do Paraná (UFPR), em Curitiba, PR, Brasil.

\section{Endereço para correspondência}

Hendryo Anderson André

Universidade Federal do Paraná

Departamento de Comunicação Social

Rua Bom Jesus, 650

Juvevê, 80035-010

Curitiba, PR, Brasil

Os textos deste artigo foram revisados pela Poá Comunicação e submetidos para validação do autor antes da publicação. 